\title{
Behavioural and Motivational Factors Associated with Weight Loss and Maintenance in a Commercial Weight Management Programme
}

\author{
James Stubbs ${ }^{1, *}$, David Brogelli ${ }^{1}$, Carolyn Pallister ${ }^{1}$, Amanda Avery $^{1}$, Aine McConnon ${ }^{2}$ and Jacquie \\ Lavin $^{1}$ \\ ${ }^{I}$ Nutrition Department, Slimming World, Clover Nook Road, Somercotes, Alfreton, Derbyshire, DE55 4RF \\ ${ }^{2}$ Food, Consumer Behaviour and Health Research Centre, Department of Psychology, University of Surrey, Guildford, \\ Surrey, GU2 $7 X H$, UK
}

\begin{abstract}
This survey examined self-reported behaviour changes associated with weight loss and maintenance in a group of 292 members of a commercial weight management organisation (CWMO). Mean (SD) joining weight was 89.0 (20.0) $\mathrm{kg}$, duration of membership was 29.1 (16.2) months and time taken to reach their current weight was 16.3 (13.5) months. Mean (SD) weight change was -15.6 (11.4) $\mathrm{kg}$ and BMI change was $-5.7(4.0) \mathrm{kg} / \mathrm{m}^{2}$, (both $\mathrm{p}<0.001$ ), which had been maintained for 11.7 (12.8) months.

Primary factors reported by participants as important in achieving their weight loss included not going hungry by satisfying appetite with low energy density food eaten ad libitum, following a flexible diet, peer-group support and tools to cope with small lapses.

Several reported eating/activity behaviours significantly correlated with weight loss maintenance (WLM). However in regression analysis, while most individual changes in eating behaviour and activity behaviour were significant predictors of weight change in this group, no variables explained more than a few percent of the variance, after adjusting for age, gender, height and starting weight.
\end{abstract}

A range of eating and activity behaviours was associated with weight loss maintenance. It is important to offer consumers flexible solutions they can adapt to their individual lifestyle needs.

Keywords: Behaviour, diet, exercise, relapse-prevention, weight maintenance.

\section{BACKGROUND}

Obesity is now recognised as being at the forefront of current "lifestyle diseases" creating a future of rising disease and chronic long-term ill health [1-4]. Obesity impacts on other lifestyle diseases such as heart disease, stroke, cancer and diabetes. This in turn affects the growing burden on health care resource that currently threatens the quality of care that national health care systems can provide $[3,5]$. Overweight, obesity and the attendant health burden to society will be major issues for governments, health professionals, the food industry and consumers for some time to come.

There has thus been an increased interest in helping people navigate towards dietary and lifestyle and other solutions to obesity e.g. [3]. Encouraging people to partake in healthier lifestyle choices would create the foundation of healthy habits that lead to greater wellbeing, quality of life and reduced expenditure for national healthcare systems. Changes in diet and activity patterns per se are the "mechanics" of behaviour change inasmuch as they are what

*Address correspondence to this author at the Nutrition Department, Slimming World, Clover Nook Road, Somercotes, Alfreton, Derbyshire, DE55 4RF; Tel: 00441773 546103; Fax: 00448448920401;

E-mail: james.stubbs@slimming-world.com people do to alter their energy balance. Of equal importance are factors that motivate people to lose weight and maintain the loss. According to Wing and Phelan, in studies that range in sample size from 225 to $\sim 1000$ about $20 \%$ of the general population do lose and maintain more than $5-10 \%$ body weight, but they are the minority of those who make the attempt [6].

It has also been suggested that the majority of those who lose weight do so independent of clinical treatment programmes, by joining commercial diet, self-help groups and/or exercise programmes [7, 8]. This apparently represents the majority of people presenting to lose weight [9]. Most available data on people who lose weight and how they maintain the loss are from highly select samples. In 1994 Brownell and Rodin noted that most data on weight loss and maintenance are from clinical trials conducted in university or clinical settings [9]. Clinical samples may show a conservative bias "because the participants are more overweight, more likely to be binge eaters, have more psychopathology, and may differ from other overweight persons in other ways not yet studied" [9]. Such individuals probably do not represent those in the general population who are overweight or even those motivated to lose weight [10-13]. They may include a high proportion of people who have failed on their own or in commercial programmes and who thus may be less predisposed to achieve long-term 
weight maintenance $[10,14]$. It is also possible there is an over-representation of a range of hormonal and other physical disorders that are associated with weight gain in clinical populations [15]. Thus only a minority of people presenting to lose weight do so by the main means that are used to collect data and so information is lacking on how most people in the community achieve and maintain weight loss. Consequently the behaviours that lead to successful weight loss maintenance and the barriers that hinder these achievements are actually not well documented [15-17].

The largest body of data on this subject, outside of university settings or clinical treatment programmes, has come from the National Weight Control Registry (NWCR) in the US, which has been used to characterise the attributes of successful weight losers and maintainers in the general population $[6,18,19]$.

Positive correlates of weight maintenance have been found to be physical activity, self monitoring, a positive coping style, continued social support, normalisation of eating patterns, reduction of co-morbidities during weight loss (which presumably affects motivation), flexible coping strategies and eating breakfast [6,20-22]. Negative correlates of weight maintenance include negative life events and family dysfunction. In the NWCR, higher levels of depression, dietary disinhibition and binge eating were also predictive of weight regain $[6,20]$.

The NWCR is likely to be more representative, than many clinical populations studied, of people in the general population who have succeeded in maintaining a significant (at least $\sim 15 \mathrm{~kg}$ ) weight loss over a sustained period of time. Nevertheless they are still a specific self-selected sub-group and it is not yet clear how generalisable findings in this group are. To gain further insight, it is important to study a number of groups of people who have maintained their weight loss.

A significant percentage of the adult population engage with diet and lifestyle solutions by participating in formal weight management programmes [7]. There has recently been a cluster of publications on the effectiveness of commercial weight management organisations (CWMOs), which have become a mainstream source of weight management solutions to a significant proportion of the general population [23-28]. The purpose of this study was to conduct an initial survey of members from a British CWMO who participated for a minimum of three months and who have on average lost $>15 \mathrm{~kg}$ in weight. The survey assessed self-reported (i) behaviour changes associated with decrease in weight and BMI, (ii) factors important or obstructive to achieving and maintaining weight loss.

\section{MATERIALS AND METHODS}

Two samples were recruited for this study. Weight loss maintainers attending a CWMO (Slimming World) were contacted using the members' website, which stated that by completing a short questionnaire, they would be entered into a draw to win $£ 100$. The advert for the survey remained on the website for 1 month. The definition of WLM was that members had to have reached and maintained their personally chosen target weight for at least 3 months. A second sample who had participated in the Slimming World arm of the Diogenes study [29] and who were happy to complete the same questionnaire also participated. They were offered the same incentive (entry into a draw to win £100). With the exception that the second sample had previously answered psychological and behavioural questions, as part of the Diogenes study, there was no difference in the interactions the researchers had with each sample. Both groups of participants had been long-term members. Mean (SD) duration of membership was 29.1 (14.1) and 38.2 (13.3) months, respectively. Participants had lost substantial amounts of weight- $16.0(9.0)$ and 15.3 (13.7) kg, respectively, which they had maintained for a mean of 11.1 (12.7) and 12.4 (13.0) months, respectively. By clicking the link to the questionnaire subjects consented to taking part in the study.

The questionnaire was specifically developed for this study, with the intention being easy to complete and in vernacular language with which the participants in the programme were familiar. Questions were designed to capture changes in behaviour that are both meaningful and useful to the participants of the programme. The questionnaire was piloted in a small number of people to ensure it was understandable and easy to administer. The questionnaire consisted of questions in which the participant selected drop-down menus to describe their age, height, level of activity, date of birth, duration of membership, time taken to reach current weight and time at current weight. Duration of membership, time taken to reach current weight and time at current weight, were computed by assuming linearity and taking the mid-point of each time category, (i.e. 6 months or less as 3 months, 6-12 months as 9 months, 12-18 months as 15 months, 18 months- 2 years as 21 months, $2-3$ years as 30 months, more than 3 years as 48 months). The remainder of the questionnaire took the form of 5-point Likert scales or checkboxes asking questions about sources of help/support and reasons for trying to lose weight, behavioural strategies that they believed have specifically helped them achieve and maintain their weight loss, previous attempts at weight loss, motivational factors important to participants in achieving weight loss and retrospective, self-reported assessments of eating/activity habits and self-esteem (using an adaptation of the Rosenberg selfesteem scale [30]) before and after the subjects lost weight. Data on self-esteem are reported elsewhere.

The participants themselves reported weight, age and height, for when they joined and at present. They were asked to consult their group records to obtain this information if they could not remember. The questionnaire was constructed and administered using Checkbox v4.4-Web Survey Software-Copyright @2007, Prezza Technologies, Inc.

From the raw data collected (height, start weight and end weight), start and end BMI, weight and percent weight change were calculated. The effects of specific behaviour changes on weight change were assessed by fitting linear models and examining the significance of fitted terms in these models, through regression analysis. Associations between specific behaviour changes and weight change were examined by Pearson correlation coefficients. All analyses were performed using Microsoft Excel (2007) and the GENSTAT 5 statistical program (Genstat 5 Rothampstead Experimental Station, Harpenden, UK). Results are expressed as mean (SD) or as percents where relevant. 
Table 1. Rank Order of Mean Response Scores, Using a 5-point Likert Scale, to the Question "Which of the Following are Important to you in Losing Weight and Maintaining your Current Weight?" $(n=292)$

\begin{tabular}{|l|c|c|}
\hline \multicolumn{1}{|c|}{ Which of the Following are Important to you in Losing Weight and Maintaining your Current Weight? } & Mean & 4.9 \\
\hline \hline For myself & 4.7 & 0.0 \\
\hline To feel better about myself & 4.7 & 0.0 \\
\hline To be healthier & 4.6 \\
\hline To feel more confident about the way I look & 4.6 & 0.0 \\
\hline To be able to wear nice clothes & 4.5 \\
\hline To increase my self-esteem & 0.0 \\
\hline To feel more energetic & 4.2 \\
\hline To live longer & 4.1 \\
\hline To feel more agile & 0.1 \\
\hline To feel less breathless & 0.1 \\
\hline To please my partner & 0.1 \\
\hline For a specific event/occasion & 4.1 \\
\hline To please my family/friends & 3.5 \\
\hline To help a treatment/operation & 2.5 & 0.1 \\
\hline To please my doctor & 0.1 \\
\hline
\end{tabular}

This study was reviewed and approved by the University of Surrey Ethics Committee.

\section{RESULTS}

\section{Participants}

There was considerable overlap in the weight, height, weight changes and similarities in responses of the two samples and they were pooled for the purpose of this analysis. The first group started and ended lighter than the second ( 80.7 vs. $98.2 \mathrm{~kg}$ and 64.7 vs. $83.0 \mathrm{~kg}$, respectively, $\mathrm{p}<0.001$ ) and took less time to reach their current weight (10.2 vs. 23.1 months, respectively, $\mathrm{p}<0.001)$. The first group was younger than the second (43.4 vs. 50.9 years, $\mathrm{p}<0.001)$. BMI changes and time at current weight were similar. For the pooled sample, 292 participants (277 women and $15 \mathrm{men}$ ) completed the survey and were included in the analysis. Mean (SD) joining weight was 89.0 (20.0) kg; BMI was $32.6(6.6) \mathrm{kg} / \mathrm{m}^{2}$; height was $1.65(0.07) \mathrm{m}$. At the point of survey age was 47.0 (12.9) years; duration of membership was 29.1 (16.2) months; time to reach current weight, 16.3 (13.5) months; time at current weight, 11.7 (12.8) months. Mean current weight and BMI was 73.4 (16.3) kg and 26.9 (5.6) $\mathrm{kg} / \mathrm{m}^{2}$, respectively. Mean (SD) weight change was $15.6(11.4) \mathrm{kg}$ and BMI change was $-5.7(4.0) \mathrm{kg} / \mathrm{m}^{2}$, (all $\mathrm{p}<0.001)$.

\section{Sources of Help and Support and Reasons for Trying to Lose Weight}

When asked how helpful or supportive various people were in helping participants lose weight, they rated out of 5 on a Likert scale, the following: their CWMO groups (3.8), their CWMO group leader (3.8), partner (3.4), children (3.3) and friends (3.2), GP (2.4) and other health professionals (2.0). Table 1 shows that the most important factors to the participants in losing and maintaining weight were related to their own sense of well-being, personal achievement ("for myself", "to feel better about myself"), health ("to be healthier") and appearance ("to feel more confident about the way I look" and "to wear nice clothes"). Losing weight for others (be it a GP or partner, family and friends) or for specific events (e.g. operation) or occasions was rated as least important.

\section{Previous Attempts at Weight Loss}

When asked "How often have you lost more than 10 pounds in a slimming attempt?" $20.5 \%$ responded "never", $41.1 \%$ said "1-2 times", $21.6 \%$ reported "3-5 times", $7.2 \%$ replied "6-10 times" and 9.6\% answered "more than 10 times". Fig. (1) shows the ranked order of reasons participants gave for giving up, if they had previously lost weight. The most important reasons that undermined their previous weight loss journey were "restricted foods", "having to eat different meals to my family" and "lack of support". Many stopped following their previous weight loss regime once they had lost weight. Factors such as "the diet was not working", "slimming did not fit in with my working life" and "lack of convenience", were deemed least important in loss of compliance with the weight loss regime they had previously followed.

\section{Factors Important to Participants in Reaching their Current Weight}

Participants were asked "Which of the following has helped you to reach your current weight?". Table 2 shows that the most important factor that participants felt had helped them achieve their current weight was not having to go hungry by satisfying appetite with low energy density food eaten ad libitum ("free-foods" in the terminology of the plan). Almost equally important was the ability to eat a healthy balanced diet that was flexible (including for social occasions), "being very honest with myself about what I eat", 


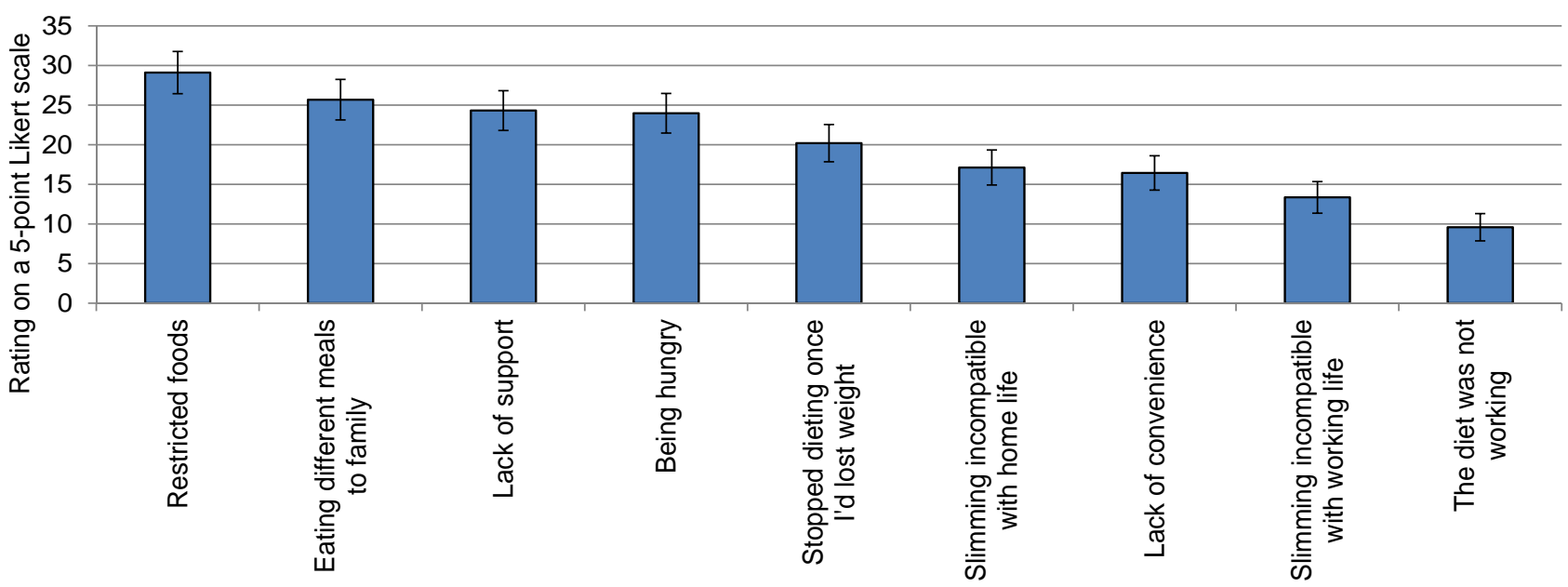

Fig. (1). Mean (SE) response to a list of questions asking "If you have lost weight previously and then given up, what made you give up?" Subjects were able to check as many of the responses as they wished. Results are presented as the percentage of the total that checked each response $(\mathrm{n}=292)$.

Table 2. Rank Order of Mean Response Scores, using a on a 5-point Likert Scale, to the Question "Which of the Following has Helped you to Reach your Current Weight?" $(n=292)$

\begin{tabular}{|c|c|c|}
\hline Which of the Following has Helped you to Reach your Current Weight? & Mean & SE \\
\hline Being able to not go hungry by filling up on "Free" Foods & 4.7 & 0.0 \\
\hline Eating a healthy, balanced diet & 4.6 & 0.0 \\
\hline Being very honest with myself about what I eat & 4.6 & 0.0 \\
\hline A flexible diet that allows me to take account of specific occasions & 4.5 & 0.0 \\
\hline Weekly group support & 4.5 & 0.1 \\
\hline Support from those around me & 4.3 & 0.1 \\
\hline Having the tools to cope with small weight gains during my weight loss journey & 4.3 & 0.1 \\
\hline Setting a realistic weight loss target & 4.2 & 0.1 \\
\hline Selecting the right foods that are a low risk for weight gain & 4.2 & 0.1 \\
\hline Regular monitoring of body weight & 4.1 & 0.1 \\
\hline Praise from those around me for my weight loss achievements & 4.0 & 0.1 \\
\hline Avoiding sugary drinks & 3.9 & 0.1 \\
\hline Regular monitoring of food intake & 3.9 & 0.1 \\
\hline Planning what I am going to eat in the next few days & 3.9 & 0.1 \\
\hline Sticking to a low fat diet & 3.8 & 0.1 \\
\hline Avoiding things that sabotage my diet & 3.7 & 0.1 \\
\hline Having the whole family involved in healthy eating & 3.6 & 0.1 \\
\hline Avoiding fast foods and takeaways & 3.5 & 0.1 \\
\hline Regular exercise & 3.5 & 0.1 \\
\hline Overcoming the feeling of guilt about being overweight & 3.4 & 0.1 \\
\hline Avoiding sweets and savoury snacks & 3.3 & 0.1 \\
\hline Avoiding alcohol & 2.3 & 0.1 \\
\hline A rigid diet that I stick to no matter what & 1.5 & 0.1 \\
\hline Calorie counted diet & 1.5 & 0.1 \\
\hline Skipping some meals (e.g. breakfast or lunch) & 1.3 & 0.0 \\
\hline Prescribed anti-obesity medication & 1.1 & 0.0 \\
\hline Over the counter anti-obesity medication & 1.0 & 0.0 \\
\hline Weight loss surgery & 1.0 & 0.0 \\
\hline Commercial meal replacements (e.g. Slimfast, Modifast, Nutrillet or other) & 1.0 & 0.0 \\
\hline
\end{tabular}




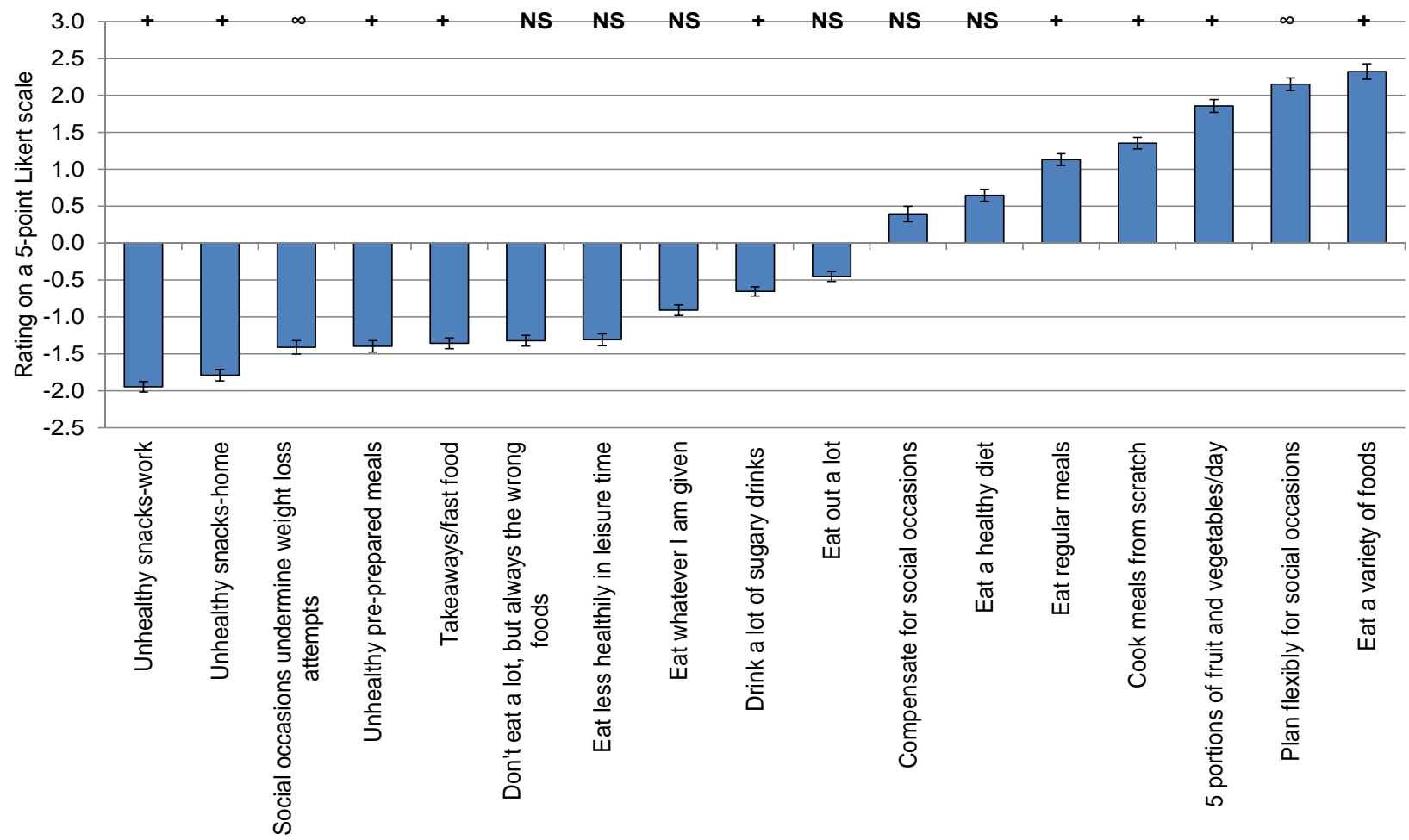

Fig. (2). Mean (SE) difference in response to a 5-point Likert scale asking participants to describe their eating behaviours before and after successful weight loss maintenance $(n=292)$. $\infty$ denotes $p<0.015$; + denotes $p \leq 0.005$.

followed by peer-group support and "having the tools to cope with small gains during my weight loss journey". To this group of participants, rigid diets, calorie counting, skipping some meals, commercial meal replacements, medication and surgery were of least importance in reaching their current weight.

\section{Self-Reported Changes in Eating and Activity Habits Associated with Weight Loss}

Participants were asked to describe their eating and activity habits since joining the CWMO. For each of the measures of eating and activity, linear regression was conducted with weight change as the outcome having adjusted for age, gender, height and initial weight. As can be seen from Fig. (2), changes in eating behaviour associated with weight loss, (percentage of the variance in weight change associated with these variables is given in parentheses), were decreases in the intake of unhealthy snacks at work (3.6\%) and home (2.6\%); attending less social occasions, which tend to undermine attempts at weight control (2.2\%); less intake of unhealthy pre-prepared meals $(2.4 \%)$ or takeaways/fast foods $(1.7 \%)$; increases in eating a bigger variety of foods (2.6\%), adopting a flexible approach to planning how much they ate at important social occasions $(1.4 \%)$, eating regular meals $(3.0 \%)$, a greater tendency to eat 5 portions of fruit and vegetables a day $(4.0 \%)$ and cooking meals from scratch (3.0\%), (all $\mathrm{p}<0.005$ except planning around social occasions, $\mathrm{p}=0.012$ ).

Changes in activity behaviour (percentage of the variance in weight change associated with these variables is given in parentheses) were a decrease in hardly ever walking anywhere $(4.7 \%)$, a decrease in hardly ever taking part in any physical sports $(1.7 \%)$ decrease in TV viewing (1.6\%) and decreased avoidance of intense activity (4.0\%). These were accompanied by increases in going out for walks a lot (4.1\%), gym/sports activities (1.4\%) and doing a lot of physical work around the house or garden (6.8\%) (Fig. 3), (all $\mathrm{p}<0.005$, except gym/sports, $\mathrm{p}=0.01$ ).

\section{Associations Between Changes in Eating, Activity Behaviour, and Change in Weight}

Because in this study all weight changes were negative (as all subjects were weight loss maintainers), an increase in behaviour showing a negative correlation with weight indicated that an increase in that behaviour was associated with weight loss. A decrease in a behaviour showing a positive correlation with weight also indicated that the change in that behaviour was associated with weight loss.

Table 3 shows the direction of eating/activity behaviour change and rank order of correlations between these outcomes and change in weight. For both eating and activity behaviour the larger correlations with weight loss were around $0.30-0.35$. For decreases in aspects of eating behaviour the largest correlations were in the intake of "unhealthy snack foods at home", "unhealthy snack foods at work", "unhealthy pre-prepared meals" and "takeaways/fast food". For increases in aspects of eating behaviour the largest correlations with weight were in "cooking meals from scratch", "eating regular meals" and eating "a bigger variety of foods". For activity the largest correlations related to moderate exertion such as walking and housework.

For weight change multiple regression models were computed. The first included age, gender, height and start weight and accounted for $35.4 \%$ of the variance in weight change. Two additional models were generated by adding change in responses for either eating behaviour and then 


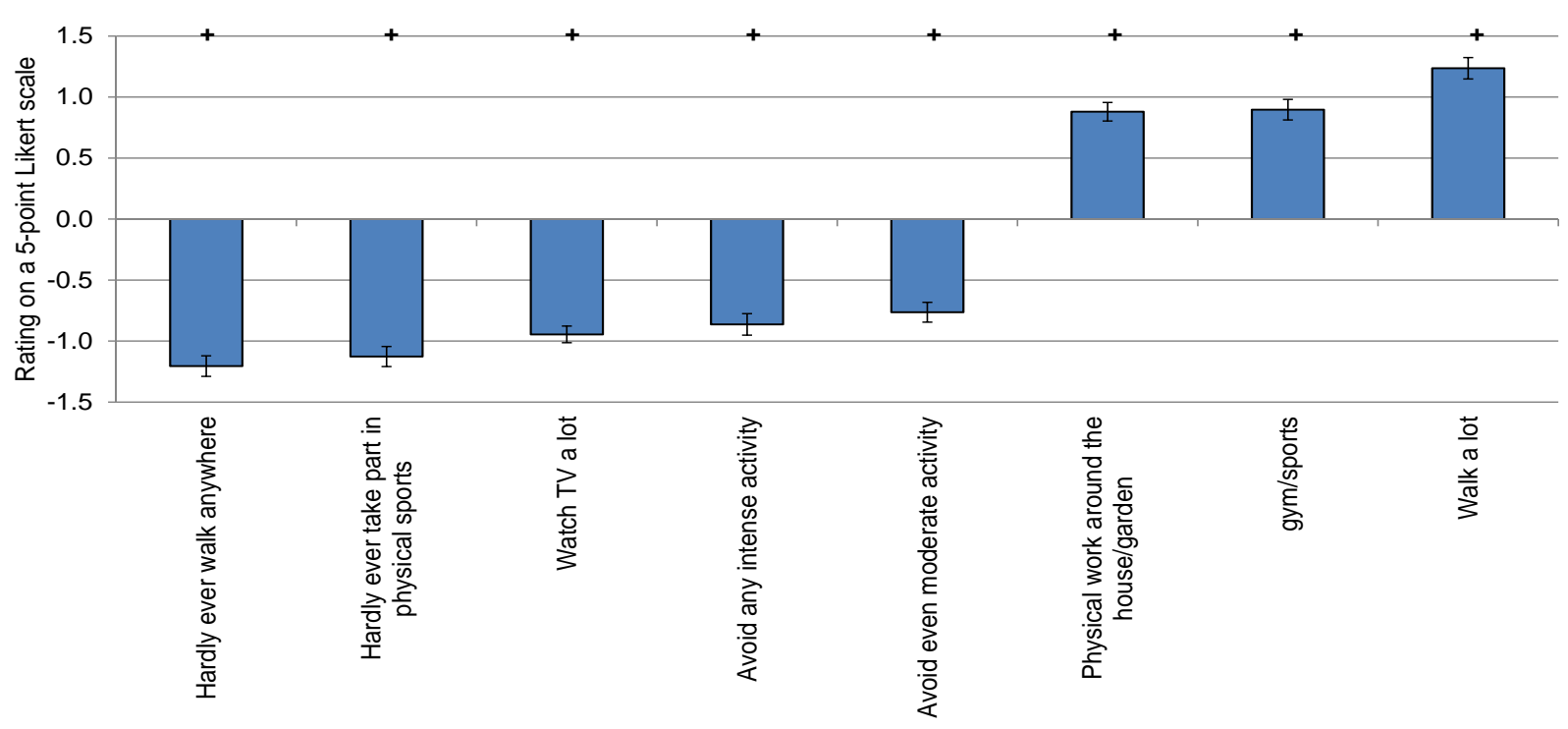

Fig. (3). Mean (SE) difference in response to a 5-point Likert scale asking participants to describe their activity behaviours before and after successful weight loss maintenance $(\mathrm{n}=292)$. $\infty$ denotes $\mathrm{p} \leq 0.01 ;+$ denotes $\mathrm{p}<0.001$.

Table 3. Correlations between Changes in Eating and Activity Behaviours and Weight Change (n=292)

\begin{tabular}{|c|c|c|c|}
\hline \multirow[t]{2}{*}{$\begin{array}{c}\text { Direction } \\
\text { Change }\end{array}$} & \multirow{2}{*}{$\frac{\text { Change in Behaviour }}{\text { Eating }}$} & \multicolumn{2}{|c|}{ Weight Change } \\
\hline & & $\mathrm{r}$ & p-value \\
\hline+ & Eat regular meals & -0.22 & $<0.01$ \\
\hline+ & Eat a variety of foods & -0.21 & $<0.01$ \\
\hline+ & Plan flexibly for social occasions & -0.15 & $<0.05$ \\
\hline+ & Compensate for social occasions & -0.13 & $<0.05$ \\
\hline+ & Eat a healthy diet & -0.05 & NS \\
\hline- & Eat out a lot & 0.04 & NS \\
\hline- & Don't eat a lot, but always the wrong foods & 0.14 & $<0.05$ \\
\hline- & Drink a lot of sugary drinks & 0.25 & $<0.01$ \\
\hline- & Takeaways/fast food & 0.25 & $<0.01$ \\
\hline- & Unhealthy pre-prepared meals & 0.26 & $<0.01$ \\
\hline- & Unhealthy snacks at work & 0.30 & $<0.01$ \\
\hline- & Unhealthy snacks at home & 0.30 & $<0.01$ \\
\hline+ & Physical work around the house/garden & -0.35 & $<0.01$ \\
\hline+ & Walk a lot & -0.25 & $<0.01$ \\
\hline- & Hardly ever walk anywhere & 0.30 & $<0.01$ \\
\hline
\end{tabular}


activity behaviour, which explained $42.6 \%, 43.6 \%$ of the variance in weight change, respectively.

\section{DISCUSSION}

\section{Weight History and Previous Attempts at Weight Loss}

It is currently estimated that one in five or six adults in the general population has accomplished WLM of at least $10 \%[6,12]$. In the present study a group of weight loss maintainers took an average of 16.3 months to lose $17.5 \%$ of their weight, which they maintained for 11.7 months at the point of study. This equates to a weight loss of $1.1 \%$ of their body weight per month on average, and it is perhaps likely that weight losses were punctuated by lapses and relapses. In the National Weight Control Registry $44.6 \%$ of those studied lost weight on their own [18] and relapses were frequent occurrences [31]. The present study and the data from the NWCR suggest that attainment of substantial weight loss is a protracted process, requiring persistent effort.

$79.5 \%$ of the study group had lost more than 10 pounds in previous weight loss attempts, prior to their current weight loss attainments. These data are consistent with the findings from the National Weight Control Registry, which suggest that the maintenance of weight loss is not easy and often takes several repeated attempts before people learn to navigate to and remain at a healthy body weight $[6,18]$. Information on why people fail to lose weight or fail to maintain weight loss is less common than descriptions of weight loss and maintenance behaviours [11, 16, 28, 32, 33]. This is despite the observation by Jeffrey et al. that the increasing prevalence of obesity and high-self reported rates of dieting in the general population suggest attempts at weight loss are being offset by failures [10]. The reasons for failed weight loss attempts are important, because one needs to learn how to cope with failure in order to succeed [34]. This is consistent with Brownell and Rodin's model of recovery from relapse $[9,35]$. Thus when this group was asked the reasons why they gave up previous weight loss attempts, restriction of foods, having to eat differently to their family and lack of support featured most highly in their answers. For some, being overweight can be seen as a chronic relapsing condition that requires long-term management, control of relapse and recognition of relapse signatures at the level of the individual [9, 35]. There is evidence that there is a physiological basis to weight relapse. Weight loss can decrease energy expenditure [36] and influence hormones that are associated with weight regain [37, 38]. For example, changes in leptin and ghrelin are associated with loss of weight and body fat. These hormonal changes have also been shown (at least in the case of one study using a very low calorie diet) to be associated with increased appetite at one-year follow up [37]. It therefore seems that weight loss induces a suite of physiological changes that would tend to favour weight regain [37-42]. Those people who successfully maintain their weight loss appear to develop patterns of motivation and behaviour that oppose relapse and promote longer-term weight maintenance.

\section{Factors Important to Participants in Losing Weight}

In the present study, subjects primarily wanted to lose weight for personal reasons. The factors that helped them reach their current weight were largely based on behavioural change and dimensions of social support. There was no single factor that was specifically important to the group as a whole. Similar patterns have been noticed elsewhere [15]. Several factors important for weight loss and maintenance were of a socially interactive nature. There is evidence in the self-help support literature indicating the importance of social relations in implementing behaviour change solutions to a number of relapsing conditions [43-48]. Jeffery et al (2000) noted that approximately a dozen studies had evaluated social support involving spouses or significant others as a means to motivate weight loss [10]. They concluded that the success of such approaches has been modest. Broader approaches to social support comparing group versus individual outcomes showed more positive results [10]. There has been a notable suggestion in the literature that social networks may be important in the development of obesity [49]. This is not without controversy [50]. For some at least, social networks may help in successful weight loss and maintenance [48, 51]. This is interesting because it may be that weight loss induces changes in physiology that pose a challenge for weight loss maintenance [37-42]. Part of the solution to that challenge may be the social and motivation factors, which support patterns of behaviour, help avoid relapse and promote longer term weight loss maintenance.

\section{Relationships Between Changes in Eating and Activity Behaviours in Association with Weight Loss and Maintenance}

In the present study several eating and activity behaviours were associated with WLM, the correlations for individual behaviours were relatively weak and none explained more than a few percent of the variance in weight loss. This indicates that as a group, while many behavioural traits were significantly associated with WLM there were few specific key eating or activity behaviours that explained much of the variance. Wing et al. and Hill et al. characterised the attributes of successful weight losers in the NWCR [6, 18, 20-22, 31]. While the range of behaviours used by weight loss maintainers (compared to those who do not maintain weight loss) is broadly similar, the specific behavioural correlates of successful weight loss maintenance in the NWCR vary [20]. Similar results have recently been reported in a sample of 225 Portuguese women by Teixeira et al. [32]. The range of behaviours exhibited by weight loss maintainers possibly suggests that different people achieve weight loss maintenance in generically similar (i.e. diet and exercise) but specifically different ways (i.e. the specific behaviours) [15]. A recent national survey of behavioural practices associated with weight loss versus weight loss maintenance in 1165 US adults suggested that weight loss and WLM may involve two different sets of weight control practices. Both weight loss and WLM were associated with a range of behaviours, but the range of behaviours leading to weight loss differed from the range of behaviours associated with successful WLM [16]. This suggests that to have maximum impact in the general population, weight control solutions need to be flexible and varied enough to accommodate the range of behaviours associated with successful weight loss and maintenance. It has been noted that there is considerable heterogeneity in the degree to which individuals exhibit specific profiles of behaviour 
change when losing weight and attempting to maintain the loss [15]. There is also variability in the extent to which they relapse, at least in the studies reviewed to date [15]. While a range of behaviours and psychological traits change significantly when weight is lost and people attempt to maintain the loss, few specific traits explain much of the variance for the whole population; intra-individual variability is too great. Such models do not explain a large proportion of the variance in weight loss outcomes, because they are population models, which attempt to elucidate common pathways for groups of people. Those groups of people seem to be engaged in a range of behaviour changes but to differing degrees [15]. It would be valuable to conduct larger studies, which follow weight loss maintainers over a longer period and examine how patterns of behaviour and motivation relate to weight relapse or continued weight loss maintenance in commercial programmes.

\section{Limitations of the Current Study}

It is likely that those who attend self-help and diet groups differ from the general population. Many of those who attend self-help groups, be it for alcohol and substance dependency, mental health or weight loss tend to be characterised by a common trait - they have a tendency to relapse [35, 43-46]. Hence they seek the on-going support and stability that the safe environment of a self-help group provides [15]. This suggests that there is both a strength and a limitation to studies such as the current analyses. This sample is a specific, self-selected sub-group, who are interesting because they do not represent the vast majority of people attempting to lose weight- they represent people who successfully lose weight in a CWMO and maintain the loss. Self-reported body weight and physical activity tend to be biased in that people (including those who are overweight) tend to underestimate their weight, under-estimate their energy intake and over-estimate their physical activity levels. Thus while the absolute levels of these estimates may be subject to some error and bias, the direction and nature of change in responses are likely to have been more robust indicators of outcomes. This study used retrospective questions to examine the responses of the same subjects regarding how they felt before and after their participation in the programme. This has to be balanced against the difficulty of identifying successful weight loss maintainers prior to their weight loss. The sample was primarily women and there are some differences between men and women in psychological and behavioural aspects of weight loss and maintenance.

\section{CONCLUSIONS}

A number of eating/activity behaviours significantly correlated with WLM. However in regression analysis, while most individual changes in eating and activity behaviour were significant predictors of weight change in this group, no variables explained more than a few percent of the variance, after adjusting for age, gender, height and starting weight. It is important to offer consumers flexible solutions they can adapt to their individual lifestyle needs.

\section{FUNDING}

Research relating to this article was part of the DiOGenes project funded by the European Commission (contract \#:
Food-CT-2005-513946) in the Food Quality and Safety Priority of the Sixth Framework Program. DiOGenes is the acronym of the project "Diet, Obesity and Genes" (www.diogenes-eu.org).

\section{CONFLICT OF INTEREST}

All authors (except AMC) work for Slimming World.

\section{ACKNOWLEDGEMENT}

We are most grateful to Dr Graham Horgan, of Biomathematics and statistics Scotland, for independent statistical analyses of and advice on these data.

\section{REFERENCES}

[1] World Health Organisation. Obesity: Preventing and Managing the Global Epidemic. Geneva: World Health Organisation 1998.

[2] National Institute for Health and Clinical Excellence. Obesity: the prevention, identification, assessment and management of overweight and obesity in adults and children. London: Department of Health 2006.

[3] Government Office for Science. tackling Obesities: Future choices. London 2007; Available from: http://www.foresight.gov.uk/Obesity/obesity_final/20.pdf [Cited 2012 Sept 16]

[4] Department of Health. Joint Health Surveys Unit (on behalf of the Department of Health). Forecasting Obesity to 2010. London: The Stationary Office 2006.

[5] Swanton K, Frost M. Lightening the load: Tackling overweight and obesity. London: National Heart Forum 2007.

[6] Wing RR, Phelan S. Long-term weight loss maintenance. Am J Clin Nutr 2005; 82: 222S-5S.

[7] Jeffery RW, Adlis SA, Forster JL. Prevalence of dieting among working men and women: the healthy worker project. Health Psychol 1991; 10: 274-81.

[8] Jeffery RW, Bjornson-Benson WM, Rosenthal BS, Lindquist RA, Kurth CL, Johnson SL. Correlates of weight loss and its maintenance over two years of follow-up among middle-aged men. Prev Med 1984; 13: 155-68.

[9] Brownell KD, Rodin J. The dieting maelstrom. Is it possible and advisable to lose weight? Am Psychol 1994; 49: 781-91.

[10] Jeffery RW, Epstein LH, Wilson GT, Drewnowski A, Stunkard AJ, Wing RR. Long-term maintenance of weight loss: current status. Health Psychol 2000; 19 (Suppl): 5-16.

[11] Kruger J, Galuska DA, Serdula MK, Jones DA. Attempting to lose weight: specific practices among U.S. adults. Am J Prev Med 2004; 26: 402-6.

[12] Kraschnewski JL, Boan J, Esposito J, et al. Long-term weight loss maintenance in the United States. Int $\mathrm{J}$ Obes Relat Metab Disord 2010; 34: 1644-54.

[13] Shah M, Hannan PJ, Jeffery RW. Secular trend in body mass index in the adult population of three communities from the upper midwestern part of the USA: the Minnesota Heart Health Program. Int J Obes Relat Metab Disord 1991; 15: 499-503.

[14] Brownell KD. Whether obesity should be treated. Health Psychol 1993; 12: 339-41.

[15] Stubbs J, Whybrow S, Teixeira P, et al. Problems in identifying predictors and correlates of weight loss and maintenance: implications for weight control therapies based on behaviour change. Obes Rev 2011; 12: 688-708.

[16] Sciamanna CN, Kiernan M, Rolls BJ, et al. Practices associated with weight loss versus weight-loss maintenance results of a national survey. Am J Prev Med 2011; 41: 159-66.

[17] Teixeira PJ, Going SB, Sardinha LB, Lohman TG. A review of psychosocial pre-treatmant predictors of weight control. Obes Rev 2005; 6: 43-65.

[18] Klem ML, Wing RR, McGuire MT, Seagle HM, Hill JO. A descriptive study of individuals successful at long-term maintenance of substantial weight loss. Am J Clin Nutr 1997; 66: 239-46.

[19] Daeninck E, Miller M. What can the National Weight Control Registry teach us? Curr Diab Rep 2006; 6: 401-4.

[20] McGuire MT, Wing RR, Klem ML, Seagle HM, Hill JO. Longterm maintenance of weight loss: do people who lose weight 
through various weight loss methods use different behaviors to maintain their weight? Int J Obes Relat Metab Disord 1998; 22: 572-7.

[21] Wyatt HR, Grunwald GK, Mosca CL, Klem ML, Wing RR, Hill JO. Long-term weight loss and breakfast in subjects in the National Weight Control Registry. Obes Res 2002; 10: 78-82.

[22] Phelan S, Wyatt HR, Hill JO, Wing RR. Are the eating and exercise habits of successful weight losers changing? Obesity 2006 ; 14: 710-6.

[23] Ahern AL, Olson AD, Aston LM, Jebb SA. Weight Watchers on prescription: an observational study of weight change among adults referred to Weight Watchers by the NHS. BMC Public Health $2011 ; 11: 434$.

[24] Heshka S, Anderson JW, Atkinson RL, et al. Weight loss with selfhelp compared with a structured commercial program: a randomized trial. JAMA 2003; 289: 1792-8.

[25] Jebb SA, Ahern AL, Olson AD, et al. Primary care referral to a commercial provider for weight loss treatment versus standard care: a randomised controlled trial. Lancet 2011; 378: 1485-92.

[26] Lewis AL, Denley J, Beach J, et al. A randomised controlled trial to compare a range of commercial or primary care led weight reduction programmes with a minimal intervention control for weight loss in obesity: the lighten up trial. Obes Rev 2011; 12 (Suppl 1): S61.

[27] Lloyd A, Khan R. Evaluation of healthy choices: a commercial weight loss programme commissioned by the NHS. Perspect Public Health 2011; 131: 177-83.

[28] Stubbs RJ, Pallister C, Whybrow S, Avery A, Lavin JH. Weight outcomes for 34,271 participants in a commercial/primary care weight management partnership scheme. Obes Facts 2011 ; 2: 113 20.

[29] Larsen TM, Dalskov S, van Baak M, et al. The Diet, Obesity and Genes (Diogenes) Dietary Study in eight European countries - a comprehensive design for long-term intervention. Obes Rev 2010; 11: 76-91.

[30] Rosenberg M. Society and the adolescent self-image. Princeton, NJ: Princeton University Press 1965.

[31] McGuire MT, Wing RR, Klem ML, Lang W, Hill JO. What predicts weight regain in a group of successful weight losers? J Consult Clin Psychol 1999; 67: 177-85.

[32] Teixeira PJ, Silva MN, Coutinho SR, et al. Mediators of weight loss and weight loss maintenance in middle-aged women. Obesity 2010; 18: 725-35.

[33] Weiss EC, Galuska DA, Khan LK, Serdula MK. Weight-control practices among U.S. adults, 2001-2002. Am J Prev Med 2006; 31 : 18-24.

[34] Gilbert P. The Compassionate Mind. London: Constable 2009.

[35] Brownell KD, Marlatt GA, Lichtenstein E, Wilson GT. Understanding and preventing relapse. Am Psychol 1986; 41: 76582 .
[36] Leibel RL, Rosenbaum M, Hirsch J. Changes in Energy Expenditure Resulting from Altered Body Weight. N Engl J Med 1995; 332: 621-8.

[37] Sumithran P, Prendergast LA, Delbridge E, et al. Long-term persistence of hormonal adaptations to weight loss. N Engl J Med 2011; 365: 1597-604.

[38] Crujeiras AB, Goyenechea E, Abete I, et al. Weight regain after a diet-induced loss is predicted by higher baseline leptin and lower ghrelin plasma levels. J Clin Endocrinol Metab 2010; 95: 5037-44.

[39] Pardina E, Lopez-Tejero MD, Llamas R, et al. Ghrelin and apolipoprotein AIV levels show opposite trends to leptin levels during weight loss in morbidly obese patients. Obes Surg 2009; 19 : 1414-23.

[40] Maestu J, Jurimae J, Valter I, Jurimae T. Increases in ghrelin and decreases in leptin without altering adiponectin during extreme weight loss in male competitive bodybuilders. Metabolism 2008; 57: $221-5$

[41] Kotidis EV, Koliakos GG, Baltzopoulos VG, Ioannidis KN, Yovos JG, Papavramidis ST. Serum ghrelin, leptin and adiponectin levels before and after weight loss: comparison of three methods of treatment-a prospective study. Obes Surg 2006; 16: 1425-32.

[42] Weigle DS, Cummings DE, Newby PD, et al. Roles of leptin and ghrelin in the loss of body weight caused by a low fat, high carbohydrate diet. J Clin Endocrinol Metab 2003; 88: 1577-86.

[43] Moos RH. Active ingredients of substance use-focused self-help groups. Addiction 2008; 103: 387-96.

[44] Moos R, Schaefer J, Andrassy J, Moos B. Outpatient mental health care, self-help groups, and patients' one-year treatment outcomes. J Clin Psychol 2001; 57: 273-87.

[45] Timko C, De Benedetti A. A randomized controlled trial of intensive referral to 12-step self-help groups: one-year outcomes. Drug Alcohol Depend 2007; 90: 270-9.

[46] Munn-Giddings C, McVicar A. Self-help groups as mutual support: what do carers value? Health Soc Care Commun 2007; 15: 26-34.

[47] Goldstrom ID, Campbell J, Rogers JA, et al. National estimates for mental health mutual support groups, self-help organizations, and consumer-operated services. Adm Policy Ment Health 2006; 33: 92-103.

[48] Humphreys K, Ribisl KM. The case for a partnership with self-help groups. Public Health Rep 1999; 114: 322-5.

[49] Christakis NA, Fowler JH. The spread of obesity in a large social network over 32 years. N Engl J Med 2007; 357: 370-9.

[50] Cohen-Cole E, Fletcher JM. Is obesity contagious? Social networks vs. environmental factors in the obesity epidemic. J Health Econ 2008; 27: 1382-7.

[51] Bahr DB, Browning RC, Wyatt HR, Hill JO. Exploiting social networks to mitigate the obesity epidemic. Obesity 2009; 17: 7238.

Received: September 30, 2012

Revised: October 22, 2012

Accepted: October 26, 2012

(C) Stubbs et al.; Licensee Bentham Open.

This is an open access article licensed under the terms of the Creative Commons Attribution Non-Commercial License (http://creativecommons.org/licenses/by-nc/3.0/) which permits unrestricted, non-commercial use, distribution and reproduction in any medium, provided the work is properly cited. 